\title{
Methadone Toxicity and Possible Induction and Enhanced Elimination in a Premature Neonate
}

\author{
Mathew George • Joseph P. Kitzmiller • \\ Michele Burns Ewald • Katherine A. O'Donell • \\ Melissa Lai Becter • Steve Salhanick
}

Published online: 17 August 2012

(C) American College of Medical Toxicology 2012

\section{Introduction}

Methadone is frequently used in neonatal intensive care units (NICUs) as both an analgesic and an agent to wean patients from prenatal exposure to opioids such as morphine and fentanyl. Massive methadone overdoses have been described in adult and pediatric patients but reports of methadone overdose in the neonate population are rare. Limited methadone clearance due to prematurity and perinatal physiology complicates both acute and chronic overdoses. However, the toxicologic data and clinical recovery presented in this report bring to light metabolism induction as a potential management tool for methadone overdose in a neonate. Literature involving methadone toxicokinetics and toxicodynamics in pediatric and neonate populations is largely limited; the currentlyavailable literature, altered pharmacokinetics in neonates, and the findings of this case will be discussed.

\section{Case Report}

A 20-day-old male neonate, born at a gestational age of 24.5 weeks and with a birth weight less than $800 \mathrm{~g}$, was intubated at birth for surfactant deficiency and developed a pneumothorax during his first week of life. Several tube thoracostomies were performed; a fentanyl drip at $19 \mu \mathrm{g}$ / $\mathrm{kg} / \mathrm{h}$ and intermittent intravenous doses of morphine at $0.1 \mathrm{mg} / \mathrm{kg}$ were administered for analgesia and sedation. Subsequently, methadone therapy was initiated on hospital day 17 in order to wean the patient from fentanyl, and 2 days later, his fentanyl dose had successfully been reduced to $10 \mu \mathrm{g} / \mathrm{kg} / \mathrm{h}$ with a methadone dose of $39 \mu \mathrm{g}$ q $6 \mathrm{~h}$ by feeding tube. A dilution error occurred on hospital day 20 (3 days after methadone had been initiated for fentanyl weaning) resulting in a single methadone dose of $7.8 \mathrm{mg}$ (approximately 200-fold the intended dose). 
Vital signs were normal immediately following the overdose; temperature was $36.4{ }^{\circ} \mathrm{C}$, pulse was 130 beats per minute, mean arterial pressure (MAP) was $47 \mathrm{mmHg}$, and oxygen saturation by pulse oximetry was $98 \%$ on $24 \%$ fraction of inspired oxygen $\left(\mathrm{FiO}_{2}\right)$. Within $2 \mathrm{~h}$ after receiving the methadone overdose, the infant began showing signs of respiratory depression (oxygen saturation in the high 80 s), requiring the following ventilator adjustments to normalize the infant's oxygen saturation: $\mathrm{FiO}_{2}$ concentration was increased from 24 to $70 \%$, positive end expiratory pressure was increased from 6 to $14 \mathrm{mmHg}$, peak inspiratory pressure was increased from 10 to $20 \mathrm{mmHg}$, and the ventilator mode was adjusted to high-frequency mode. This sudden change in respiratory status prompted the care team to recheck the methadone dilution calculations and administration; the iatrogenic dilution error was discovered, management of the massive methadone overdose continued, and urine and serum samples were collected for determining levels of methadone and its primary metabolite. Analyte levels (Table 1) were detected utilizing gas chromatography-mass spectrometry.

Four episodes of clonic movements of the left arm and leg were observed coinciding with transient periods of hypoxemia. Continuous electroencephalogram (ECG) monitoring did not reveal activity suggestive of seizure during the clonic episodes. Asymmetric (right greater than left) burst suppression patterns, with maximal suppression intervals occurring at $4.5 \mathrm{~h}$ post methadone overdose, were observed but did not coincide with the clonic episodes. Approximately $12 \mathrm{~h}$ after the methadone overdose, phenobarbital $(5 \mathrm{mg} /$ $\mathrm{kg} \mathrm{q} 12 \mathrm{~h}$ by feeding tube) was started as treatment for presumed seizures, and hemodynamic instability (MAPs near $20 \mathrm{mmHg}$ ) necessitated dopamine infusion with requirements as high as $22 \mu \mathrm{g} / \mathrm{kg} / \mathrm{min}$. The infant's cell blood counts, electrolytes, ECGs, and urine output remained within normal limits. Ventilatory and hemodynamic status improved within $24 \mathrm{~h}$ after the methadone overdose. Dopamine was subsequently discontinued, the ventilator setting was returned to conventional mode, and the infant recovered fully from the methadone overdose.

\section{Discussion}

As an analgesic or as treatment for neonatal opiate withdrawal syndrome, methadone therapy is commonly used in tertiary care center NICUs. In the pediatric population, methadone is considered superior to many other anesthetics $[1,2]$. In fact, both pain scores and supplemental analgesia use were significantly lower for postoperative pediatric patients receiving methadone compared to other agents [2-6].

Similar to the toxicity associated with the other opioids, methadone toxicity results in respiratory depression, mental status depression, dysphoria, pruritus, and hypotension [7]. Development of nonketotic hyperglycemia in pediatric patients has also been reported in some methadone overdose cases, and QT prolongation (although infrequently reported) is another grave concern as it may lead to potentially fatal arrhythmias [8-12]. In this case report, opioid respiratory depression likely resulted in the infant's need for increased ventilatory support. However, increased chest rigidity, a rare adverse effect associated with methadone overdose, may have contributed as well. In one report, a 3-week-old neonate (gestational age of 35 weeks) required intense bag mask ventilation after a 10 -fold error in methadone dosing, and chest wall rigidity was evident by a lack of chest rise despite substantial bag pressure and an occluded pop-off valve [13]. Seizures are not commonly reported in cases of methadone exposure but may result from methadone-associated cerebral hypoxia or decreased seizure threshold. Although it is not known whether methadone metabolites have excitatory properties, the glucuronide metabolites of both morphine and hydromorphone are known to cause neuroexcitatory effects (myoclonus, seizures) [14], and myoclonus has been reported in cases of methadone overexposure [15]. Nonetheless, the etiology of the clonic movements observed in this case is uncertain.
Table 1 Methadone and metabolite concentrations in serum and urine after methadone overdose

Methadone and 2-ethylidene-1, 5-dimethyl-3, 3-

diphenylpyrolidine $(E D D P)$ levels were determined utilizing gas chromatography-mass spectrometry. Analyte levels listed as $<$ LOD were below the level of detection $(L O D)$

\begin{tabular}{|c|c|c|c|c|}
\hline \multirow[t]{2}{*}{ Time after methadone overdose (hours) } & \multicolumn{2}{|l|}{ Urine } & \multicolumn{2}{|l|}{ Serum } \\
\hline & $\begin{array}{l}\text { Methadone } \\
(\mathrm{ng} / \mathrm{mL})\end{array}$ & $\begin{array}{l}\text { EDDP } \\
(\mathrm{ng} / \mathrm{mL})\end{array}$ & $\begin{array}{l}\text { Methadone } \\
(\mathrm{ng} / \mathrm{mL})\end{array}$ & $\begin{array}{l}\text { EDDP } \\
(\mathrm{ng} / \mathrm{mL})\end{array}$ \\
\hline 6 & $>5,000$ & 783 & & \\
\hline 12 & \multicolumn{4}{|c|}{ phenobarbital administered } \\
\hline 20 & $>5,000$ & 1,507 & 340 & $<\mathrm{LOD}$ \\
\hline 48 & & & 145 & $<\mathrm{LOD}$ \\
\hline 51 & $>5,000$ & $<\mathrm{LOD}$ & & \\
\hline 72 & & & 89 & $<\mathrm{LOD}$ \\
\hline 73 & 4,302 & $<\mathrm{LOD}$ & & \\
\hline 141 & 389 & $<$ LOD & & \\
\hline
\end{tabular}


The pharmacokinetic parameters of methadone in children have largely been extrapolated from adult studies, and the pharmacokinetics of methadone in premature neonates has not been formally studied.

Methadone is a lipophilic drug and the steady-state volume of distribution ranges between 1.0 and $8.0 \mathrm{~L} / \mathrm{kg}$ in adults. It is predominantly bound to $\alpha 1$-acid glycoprotein $(85-90 \%$ in adults) and is secreted in saliva, breast milk, amniotic fluid, and umbilical cord plasma. As shown in Fig. 1, methadone is primarily metabolized by $\mathrm{N}$-demethylation to an inactive metabolite, 2-ethylidene-1,5-dimethyl-3,3-diphenylpyrrolidene (EDDP). The cytochrome P450 enzymes (CYP), primarily CYP3A4, CYP2B6, and CYP2C19 and to a lesser extent CYP2C9 and CYP2D6, are responsible for conversion of methadone to EDDP and other inactive metabolites including 2-ethyl-5-methyl-3,3-diphenylpyroline, methadol, and normethadol. Minimal biliary and fecal excretion does occur, but methadone and its metabolites are predominantly excreted in urine. Pharmacokinetic data reported in cases of methadone overdose in adult and pediatric cases suggests its elimination is saturable $[3,5,16-20]$. The terminal half-life reported in adult populations is highly variable; a range of $8-59 \mathrm{~h}$ is reported in several studies. In the few cases of methadone overexposure reported in neonates, the pharmacometrics vary widely and suggest age-dependence. An elimination half-life of 41 was reported in a neonate [5], and a range of 3.5-60 h is reported for pediatric patients [3].

Several significant pharmacologic differences exist among neonate, pediatric, and adult populations. Drug absorption of orally administered drugs is delayed in infants secondary to increased gastric emptying time. Drug absorption, however, is increased secondary to increased gastric transit time. Immature intestinal mucosa can result in

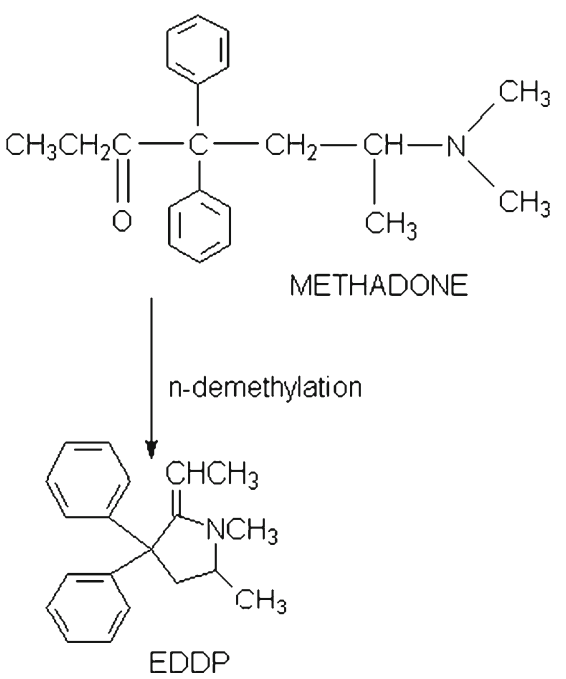

Fig. 1 Methadone's primary metabolic pathway: Conversion $(\mathrm{N}-$ demethylation) of methadone to 2-ethylidene-1, 5-dimethyl-3, 3diphenylpyrolidine $(E D D P)$ decreased rates of absorption due to altered active transport and permeability. Intramuscular absorption is delayed in newborns due to peripheral vasomotor instability, decreased muscular contraction, and circulatory insufficiency. Percutaneous absorption is increased in newborns due to decreased thickness of stratum corneum, increased skin hydration, and increased surface area per weight. Neonates have an increased percentage of body water resulting in an increased volume of distribution for water-soluble drugs. They have a lower percentage of body fat resulting in a lower volume of distribution for lipid-soluble drugs. Decreased protein-binding capacity in neonates results in an increase in the amount of unbound drug, potentially leading to increased physiologic response and elimination. Drug metabolism is also altered in the neonate population: enzyme activity (hydrolysis, hydroxylation, N-demethylation, glucuronidation, and glycine conjugation) is significantly reduced in neonates. Differences in other specific metabolic enzymes have been well characterized: CYP3A7 and CYP4A1 levels are high in the fetus, peak at birth, and then decrease throughout childhood; CYP2D6 and CYP2E1 levels are low in the fetus, surge at birth, and continue to increase throughout childhood; CYP3A4, CYP2C, CYP2B, and CYP1A2 are low in the fetus and at birth and slowly rise throughout childhood. Drug excretion is markedly decreased in neonates: typical glomerular filtration rate is about $2-4 \mathrm{~mL} / \mathrm{min}$ at birth, $8-12 \mathrm{~mL} / \mathrm{min}$ at 3 days, and $120 \mathrm{~mL} / \mathrm{min}$ by about 5 months of age.

In addition to several of the age-related pharmacokinetic differences discussed above, the pharmacology of methadone in this neonate may also have been affected by a drugdrug interaction. At the time of the overdose, the only concomitant medication was caffeine, being given for apnea of prematurity. Although caffeine is known to induce CYP1A2, this enzyme plays no role in the metabolism of methadone. The only other medication administered during the management of the methadone overdose was phenobarbital, a known inducer of CYP3A. Although CYP3A4 metabolism is known to be negligible in neonates whereas CYP3A7 is abundant, phenobarbital may have induced metabolism of both CYP3A enzymes. Compared to CYP3A7, CYP3A4 more readily metabolizes methadone. However, significant $\mathrm{N}$-demethylation did occur in this neonate and was likely the result of CYP3A and CYP2D6 (the only other methadone-metabolizing enzyme likely to be present in a neonate). From the data in Table 1, the serum half-life of methadone for this infant was about $30 \mathrm{~h}$, considerably lower than the $40 \mathrm{~h}$ reported in the other neonate overdose case. Whether the metabolism was hepatic or extrahepatic (e.g., renal) is unclear. The absence of EDDP in the serum does not rule out hepatic metabolism as the kidney readily clears EDDP from blood. The contemporary literature related to organ-specific metabolism and developmental 
pharmacokinetics does not support the idea of significant extra-hepatic metabolism. The extent that CYP3A induction may have been responsible for the reduced half-life is unclear; nonetheless, enzyme induction could be considered a potential adjunct tool for managing methadone overdoses. A low percentage of body fat in neonates results in lower distribution of fat-soluble drugs, and this too likely played a role in the relatively quick elimination of methadone in this case. Lastly, it is important to discuss how similar methadone overdoses can be avoided: Care teams that implement mandatory medication dilution witnessing (e.g., a second member to verify dilution calculations) in nonemergent care situations are arguably less likely to commit this type of error.

\section{Conclusion}

Methadone toxicity in premature infants is rarely reported. As we have reported, in tertiary care settings, massive methadone exposure can be effectively managed with intensive and meticulous monitoring and appropriate supportive and symptomatic intervention. In future studies, phenobarbital may be studied as an agent for enhancing methadone detoxification.

\section{Conflict of Interest None.}

\section{References}

1. Osborn DA, Jeffery HE, Cole MJ (2005) Sedatives for opiate withdrawal in newborn infants. Cochrane Database Syst Rev 20 (3):CD002053

2. Chana SK, Anand KJS, Rutter N (2001) Can we use methadone for analgesia in neonates? Arch Dis Child Fetal Neonatal Ed 85:79-81

3. Berde CB, Beyer JE, Bournaki MC, Levin CR, Sethna NF (1991) Comparision of morphine and methadone for prevention of postoperative pain in 3 to 7 years old children. J Pediatr 119:136-141
4. Shir Y, Shenkman Z, Shavelson V, Davidson EM, Rosen G (1998) Oral methadone for the treatment of severe pain in hospitalized children: a report of 5 cases. Clinical J Pain 14:350-353

5. Anand KJS (2007) Pharmacological approaches to the management of pain in the neonatal intensive care unit. J Perinatol 27:4-11

6. Wunsch MJ, Martha J (2006) A chart review comparing paregoric to methadone in the treatment of neonatal opioid withdrawal. J Addict Dis 25(3):27-33

7. Blatman S (1974) Narcotic poisoning of children (1) through accidental ingestion of methadone and (2) in utero. Pediatrics 54:329-332

8. Tiras S, Haas V, Chevret L, Decobert M, Buisine M, Devictor D, Durand P, Tissières P (2006) Nonketotic hyperglycemic coma in toddlers after unintentional methadone ingestion. Ann Emerg Med 48(4):448-451

9. Roden DM (2004) Drug-induced prolongation of the QT interval. N Eng J Med 350:1013-1022

10. Manfredi PL, Gonzales GR, Payne R (2001) Reversible spastic paraparesis induced by high-dose intravenous methadone. J Pain 2 (1):77-79

11. Lalkin A, Bhushan MK, Koren G (1999) Contamination of antibiotics resulting in severe pediatric methadone poisoning. The Ann of Pharmacol 33:314-317

12. Ehret GB, Voide C, Gex-Fabry M, Chabert J, Shah D, Broers B, Piguet V, Musset T, Gaspoz JM, Perrier A, Dayer P, Desmeules JA (2006) Drug-induced long QT syndrome in injection drug users receiving methadone: high frequency in hospitalized patients and risk factors. Arch Intern Med 166(12):1280-1287

13. Lynch RE, Hack RA (2010) Methadone induced rigid-chest syndrome after substantial overdose. Pediatrics 126(1):e232e234

14. Smith MT (2000) Neuroexcitatory effects of morphine and hydromorphone: evidence implicating the 3-glucuronide metabolites. Clin Exp Pharmacol Physiol 27(7):524-528

15. Ito S, Liao S (2008) Myoclonus associated with high dose parenteral methadone. J of Palliat Med 11(6):838-841

16. Micromedex ${ }^{\mathbb{B}}$ Healthcare Series (Internet database). Version5.1. Greenwood Village, Colo. Thomson Reuters (Healthcare) Inc. Methadone and related compounds (accessed on August 21,2011)

17. Ferrari A, Coccia CP, Bertolini A, Sternieri E (2004) Methadonemetabolism, pharmacokinetics and interactions. Pharmacol Res 50 (6):551-559

18. Disposition of toxic drugs and chemicals in man, 7th edn. Randall $\mathrm{C}$ Baselt PhD. Biomedical publications: Foster City California 2004. Methadone pp 678-682

19. Kreek MJ (1986) Drug interactions with methadone in humans. NIDA Res Monogr 68:193-225

20. Plummer JL, Gourlay GK, Cherry DA, Cousins MJ (1988) Estimation of methadone clearance: application in the management of cancer pain. Pain 33(3):313-321 